\title{
Supercapacitor/biofuel cell hybrid device employing biomolecules for energy conversion and charge storage
}

Shen, Fei; Pankratov, Dmitry; Pankratova, Galina; Toscano, Miguel D.; Zhang, Jingdong; Ulstrup, Jens; Chi, Qijin; Gorton, Lo

Published in:

Bioelectrochemistry

Link to article, DOI:

10.1016/j.bioelechem.2019.03.009

Publication date:

2019

Document Version

Peer reviewed version

Link back to DTU Orbit

Citation (APA):

Shen, F., Pankratov, D., Pankratova, G., Toscano, M. D., Zhang, J., Ulstrup, J., Chi, Q., \& Gorton, L. (2019). Supercapacitor/biofuel cell hybrid device employing biomolecules for energy conversion and charge storage. Bioelectrochemistry, 128, 94-99. https://doi.org/10.1016/j.bioelechem.2019.03.009

\section{General rights}

Copyright and moral rights for the publications made accessible in the public portal are retained by the authors and/or other copyright owners and it is a condition of accessing publications that users recognise and abide by the legal requirements associated with these rights.

- Users may download and print one copy of any publication from the public portal for the purpose of private study or research.

- You may not further distribute the material or use it for any profit-making activity or commercial gain

- You may freely distribute the URL identifying the publication in the public portal 


\section{Accepted Manuscript}

Supercapacitor/biofuel cell hybrid device employing biomolecules for energy conversion and charge storage

Fei Shen, Dmitry Pankratov, Galina Pankratova, Miguel D. Toscano, Jingdong Zhang, Jens Ulstrup, Qijin Chi, Lo Gorton

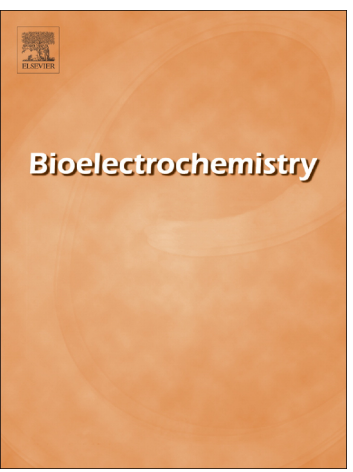

PII:

S1567-5394(18)30447-X

DOI: https://doi.org/10.1016/j.bioelechem.2019.03.009

Reference:

BIOJEC 7267

To appear in:

Bioelectrochemistry

Received date:

29 September 2018

Revised date:

26 March 2019

Accepted date:

26 March 2019

Please cite this article as: F. Shen, D. Pankratov, G. Pankratova, et al., Supercapacitor/ biofuel cell hybrid device employing biomolecules for energy conversion and charge storage, Bioelectrochemistry, https://doi.org/10.1016/j.bioelechem.2019.03.009

This is a PDF file of an unedited manuscript that has been accepted for publication. As a service to our customers we are providing this early version of the manuscript. The manuscript will undergo copyediting, typesetting, and review of the resulting proof before it is published in its final form. Please note that during the production process errors may be discovered which could affect the content, and all legal disclaimers that apply to the journal pertain. 


\title{
Supercapacitor/biofuel cell hybrid device employing biomolecules for energy conversion and charge storage
}

Fei Shen ${ }^{\mathrm{a}}$, Dmitry Pankratov ${ }^{\mathrm{a}}$, Galina Pankratova ${ }^{\mathrm{b}}$, Miguel D. Toscano ${ }^{\mathrm{c}}$, Jingdong Zhang ${ }^{\mathrm{a}}$, Jens Ulstrup ${ }^{\mathrm{a}}$, Qijin Chi, ${ }^{\mathrm{a}, *}$ cq@kemi.dtu.dk, Lo Gorton ${ }^{\mathrm{b}, *}$ lo.gorton@ biochemistry.lu.se

${ }^{a}$ Department of Chemistry, Technical University of Denmark, Building 207, Kemitorvet, DK2800 Kongens Lyngby, Denmark

${ }^{\mathrm{b}}$ Department of Biochemistry and Structural Biology, Lund University, P.O. Box 124, SE-22100

Lund, Sweden

${ }^{c}$ Novozymes A/S, Krogshoejvej 36, 2880 Bagsværd, Denmark

${ }^{*}$ Corresponding authors.

\begin{abstract}
We report on a hybrid bioelectrochemical system that integrates an energy converting part, viz. a glucose/oxygen enzymatic fuel cell, with a charge-storing component, in which the redox features of the immobilized redox protein cytochrome $c$ (cyt $c$ ) were utilized. Bilirubin oxidase and pyrroloquinoline quinone-dependent glucose dehydrogenase (PQQ-GDH) were employed as the biocatalysts for dioxygen reduction and glucose oxidation, respectively. A bi-protein PQQ$\mathrm{GDH} / \mathrm{cyt} c$ signal chain was created that facilitates electron transfer between the enzyme and the electrode surface. The assembled supercapacitor/biofuel cell hybrid biodevice displays a 15 times higher power density tested in the pulse mode compared to the performance achieved from the continuously operating regime (4.5 and $0.3 \mu \mathrm{W} \mathrm{cm} \mathrm{cm}^{-2}$, respectively) with an $80 \%$ residual activity after 50 charge/discharge pulses. This can be considered as a notable step forward in the field of glucose/oxygen membrane-free, biocompatible hybrid power sources.
\end{abstract}

Keywords: enzymatic fuel cell, bilirubin oxidase, glucose dehydrogenase, cytochrome $c$, hybrid bioelectrochemical system 


\section{Introduction}

Supercapacitive biofuel cells (SBCs) constitute a rapidly progressing segment of hybrid bioelectrochemical systems employing dual-function electrodes [1]. In these systems the internal electrode capacitance is actively utilized to accumulate electric charge generated by the bioelement (enzyme or microbial cells) directly immobilized on the capacitive segment of the SBC or physically separated, but electrically interconnected with this segment. Starting from the pioneering work that has disclosed the influence of electrode capacitance on power output of microbial fuel cells [2] and by employing cytochromes produced by living bacteria for charge storage [3,4], the SBC concept was further expanded to photobioelectrochemical cells $[5,6]$ and enzymatic fuel cells (vide infra). Development of enzymatic SBCs (ESBCs) has become a field of special interest with regards to potentially implantable or wearable power sources operating under certain conditions, when established enzymatic fuel cells are unable to provide a robust power output to supply miniature electronics. Operation in pulse mode, when the charge accumulated during low-power continuous operation is extracted via short high-power bursts, allows overcoming these restrictions and an expanding application niche of enzymatic power sources [7].

The charge-storing components of ESBCs reported so far are mainly based on the supercapacitive features of carbon nanotube-based materials [8-11], metal [12] and metal oxide nanoparticles [13] or on the faradaic behavior of osmium-complex-modified redox polymers [14-16]. However, in spite of recent achievements in the development of ESBCs and the proofof-principle demonstration of a variety of approaches of fabrication and utilization of ESBCs, the biocompatibility and biodegradability of these materials remain a challenge, and most reported ESBC types require additional modification to become useable under implantable conditions or in contact with physiological fluids [17]. Moreover, the combination of a high-capacitive chargestoring element with a low-performance enzymatic part could result in an unacceptably long equilibration time after each discharging pulse [9].

In view of these shortcomings, further development of SBCs and ESBCs requires introduction of redox active or pseudocapacitive proteins to build renewable and entirely biodegradable charge storing bioelements with a broadly variable capacitance. The recent reported example of an 
ultrathin supercapacitor that incorporates the advantages of the pseudocapacitive features of immobilized myoglobin [18], substantiates the practical attainability of this concept.

In earlier work, graphene paper (GP) based materials have shown unique properties, i.e. robust mechanical strength, high electrical conductivity, tunable flexibility, low weight and low cost, together with potential applications in biomimetic composites, electrocatalytic sensors and energy storage devices [19-24]. Moreover, the fabrication method of GP is scalable and reproducible. Employing freestanding GP as a current collector and enzyme loading material offers furthermore a wider application of ESBCs in implanted or flexible medical devices.

In this work, we demonstrate, to the best of our knowledge, the very first functional ESBC in which biological materials are exploited for both energy conversion and charge storage. To convert this concept into action, bilirubin oxidase (BOx) and pyrroloquinoline quinonedependent glucose dehydrogenase (PQQ-GDH) were utilized as dioxygen reducing and glucose oxidizing bioelements, respectively. Notably cytochrome $c$ (cyt $c$ ), a small redox protein (MW ca. $12 \mathrm{kDa}$ ), was employed simultaneously as an anodic electron transfer mediator and a charge storing component.

\section{Experimental}

\subsection{Chemicals and enzymes}

1,4-Piperazinediethanesulfonic acid (PIPES), D-(+)-glucose, and sodium dihydrogen phosphate dihydrate, sodium hydroxide, calcium chloride dihydrate, sodium monohydrogen phosphate dihydrate, hydrazine hydrate, and cyt $c$ from horse heart were purchased from Sigma-Aldrich, Germany. Graphene oxide (GO) powder was either in-house prepared [25] or obtained from the Sixth Element Inc (China). PQQ-GDH (1020 $\left.\mathrm{U} \mathrm{mg}^{-1}\right)$ from Acinetobacter calcoaceticus was purchased from Sorachim SA (Switzerland). BOx (167 $\mathrm{U} \mathrm{mg}^{-1}$ ) from Myrothecium verrucaria was produced and purified by Novozymes A/S (Denmark) based on a reported protocol [26]. All chemicals were at least of analytical grade and used as received. All aqueous solutions were prepared using Milli-Q water $(18.2 \mathrm{M} \Omega \mathrm{cm})$. Air-saturated $10 \mathrm{mM}$ phosphate buffer $\left(\mathrm{NaH}_{2} \mathrm{PO}_{4}\right.$, $\mathrm{Na}_{2} \mathrm{HPO}_{4}$ at $\mathrm{pH}$ 7.4) was used in all experiments, unless stated otherwise.

\subsection{Preparation of graphene paper}


GP was prepared according to a previously reported method with some modification [21,24]. Briefly, $20 \mathrm{~mL}$ of a $1 \mathrm{mg} \mathrm{mL} \mathrm{m}^{-1}$ graphene oxide (GO) suspension was vacuum filtrated to assemble a GO film with a diameter of $45 \mathrm{~mm}$. It was then reduced by a hydrazine steam in an autoclave at $99{ }^{\circ} \mathrm{C}$ for $2 \mathrm{~h}$, followed by high temperature annealing at $600{ }^{\circ} \mathrm{C}$ for $1 \mathrm{~h}$ in an oven under a flow of Ar. An average thickness of the obtained GP was $64 \pm 20 \mu \mathrm{m}$ measured by using Mitutoyo Thickness Gauge 547-321 (Mitutoyo, Aurora, IL, USA) Finally, the reduced GO films were cut into $0.5 \times 1 \mathrm{~cm}$ rectangles for further biomodification.

\subsection{Preparation of bioanode and biocathode}

Bioanodes were fabricated by physical adsorption of cyt $c$ and PQQ-GDH onto the electrodes. An aliquot of a $10 \mu \mathrm{L}$ of a cyt $c$ solution $\left(2.5 \mathrm{mg} \mathrm{mL}^{-1}\right.$ in $10 \mathrm{mM}$ phosphate buffer, $\left.\mathrm{pH} 7.4\right)$ was first drop cast onto the GP electrodes and kept in a moisturized chamber at $4^{\circ} \mathrm{C}$ for $2 \mathrm{~h}$. The cyt $c$ modified GP electrodes (GP-cyt $c$ ) were next rinsed three times with buffer to remove any unbound protein and further modified in order to prepare both the anode and the cathode electrodes. For preparation of the bioanode $10 \mu \mathrm{L}$ of a PQQ-GDH solution $\left(4 \mathrm{mg} \mathrm{mL}^{-1}\right.$ in $20 \mathrm{mM}$ PIPES buffer containing $3 \mathrm{mM} \mathrm{CaCl}$ as stabilizer, $\mathrm{pH}$ 7.0) was drop-cast onto the GP-cyt $c$ electrode, then kept in a moisturized chamber at $4^{\circ} \mathrm{C}$ for $30-40 \mathrm{~min}$, and then rinsed with phosphate buffer before use. For preparation of the biocathode $10 \mu \mathrm{L}$ of a BOx solution (3.61 mg $\mathrm{mL}^{-1}$ in $20 \mathrm{mM}$ Tris buffer, containing $100 \mathrm{mM} \mathrm{Na}_{2} \mathrm{SO}_{4}, \mathrm{pH} \mathrm{8.0)}$ was spread on the other side of the GP-cyt $c$ electrode and kept in a moisturized chamber at $4^{\circ} \mathrm{C}$ for $30-40 \mathrm{~min}$. After enzyme adsorption, the cathodes were rinsed with buffer to remove loosely bound enzyme.

\subsection{Electrochemical data}

All electrochemical measurements were performed at room temperature $\left(23 \pm 2^{\circ} \mathrm{C}\right)$ using an Autolab PGSTAT30 potentiostat (Metrohm AG, Utrecht, The Netherlands), controlled by the GPES software. For half-cell tests, a three-electrode system was used, where the bioanode or the biocathode was used as the working electrode, a platinum plate and an $\mathrm{Ag} \mid \mathrm{AgCl}\left(\mathrm{KCl}_{\text {sat }}\right)$ as counter and reference electrode, respectively. All potentials in this work are referred to the $\mathrm{Ag} \mid \mathrm{AgCl}, \quad \mathrm{KCl}_{\text {sat }}$ electrode $(+197 \mathrm{mV}$ relative to the standard hydrogen electrode $)$. The electrochemical performance of the assembled membrane-less ESBC was evaluated by using a two-electrode system with the bioanode and the biocathode immersed in the same electrolyte 
solution. The voltage changes during the charge/discharge cycling were monitored simultaneously with galvanostatic potentiometry using a digital multimeter (UNI-T, UT61 Series, China).

\section{Results and discussion}

\subsection{Electrochemical behavior of the bioanode}

Cyt $c$, a water-soluble redox protein, is crucial in the respiratory electron transport chain in microorganisms and animals. The heme group of cyt $c$ is able to accept and donate electrons as a redox mediator, which makes cyt $c$ a suitable intermediate molecule to facilitate electron transfer between electrode surfaces and certain enzymes. Biomimetic signal chains between cyt $c$ and a variety of other biomolecules such as sugar dehydrogenases, blue multicopper oxidases, sulfite oxidase, isolated photosystems and bacterial cells have been reported, allowing efficient interprotein electron transfer [27-35].

In the current work, we intended to use cyt $c$ for shuttling electrons between PQQ-GDH and the GP electrode. Cyclic voltammetry (CV) was first employed to investigate the electrochemical behavior of cyt $c$ physisorbed on the GP electrode. A pair of redox peaks at $\mathrm{E}_{1 / 2}=0.075 \mathrm{~V}$ (Figure 1A) reflects an efficient direct electron transfer (DET) reaction between cyt $c$ and the GP electrode. PQQ-GDH was next immobilized on the cyt $c$ layer to fabricate the glucose oxidizing bioanode (PQQ-GDH-cyt $c$-GP) and investigate the electrochemical communication between PQQ-GDH and cyt $c$ in a glucose-containing electrolyte. Figure $1 \mathrm{~B}$ shows that the bioelectrocatalytic currents increase with an increase in glucose concentration. Control experiments when only cyt $c$ was immobilized on the GP electrodes show no oxidation response towards glucose (Figure 1A). Moreover, PQQ-GDH did not undergo DET in the absence of the redox protein. As a result, cyt $c$ was concluded to establish an efficient electron transfer pathway connecting the redox center of PQQ-GDH and the GP surface. The PQQ-GDH-cyt $c$-GP bioanode displays an onset potential of $0.02 \pm 0.01 \mathrm{~V}$ and a catalytic current of about $0.3 \mu \mathrm{A} \mathrm{cm} \mathrm{cm}^{-2}$ at $0.3 \mathrm{~V}$ in the presence of $1 \mathrm{mM}$ glucose. This current value is about 2 orders of magnitude larger than that obtained from PQQ-GDH coupled to cyt $c$ /DNA-multilayer systems in the presence of glucose in the same concentration [28]. When the concentration reaches $3 \mathrm{mM}$, the 
response of the immobilized PQQ-GDH towards glucose is close to the saturation value (Supplementary Figure S1). The calculated apparent Michaelis constant (Km) is around $0.92 \mathrm{mM}$ obtained from the Michaelis-Menten kinetics (Supplementary Equation S1). This value is smaller than that for the solubilized enzyme $(4.8 \mathrm{mM})$, which can be attributed to the limitation from the protein-protein electron transfer process [28].
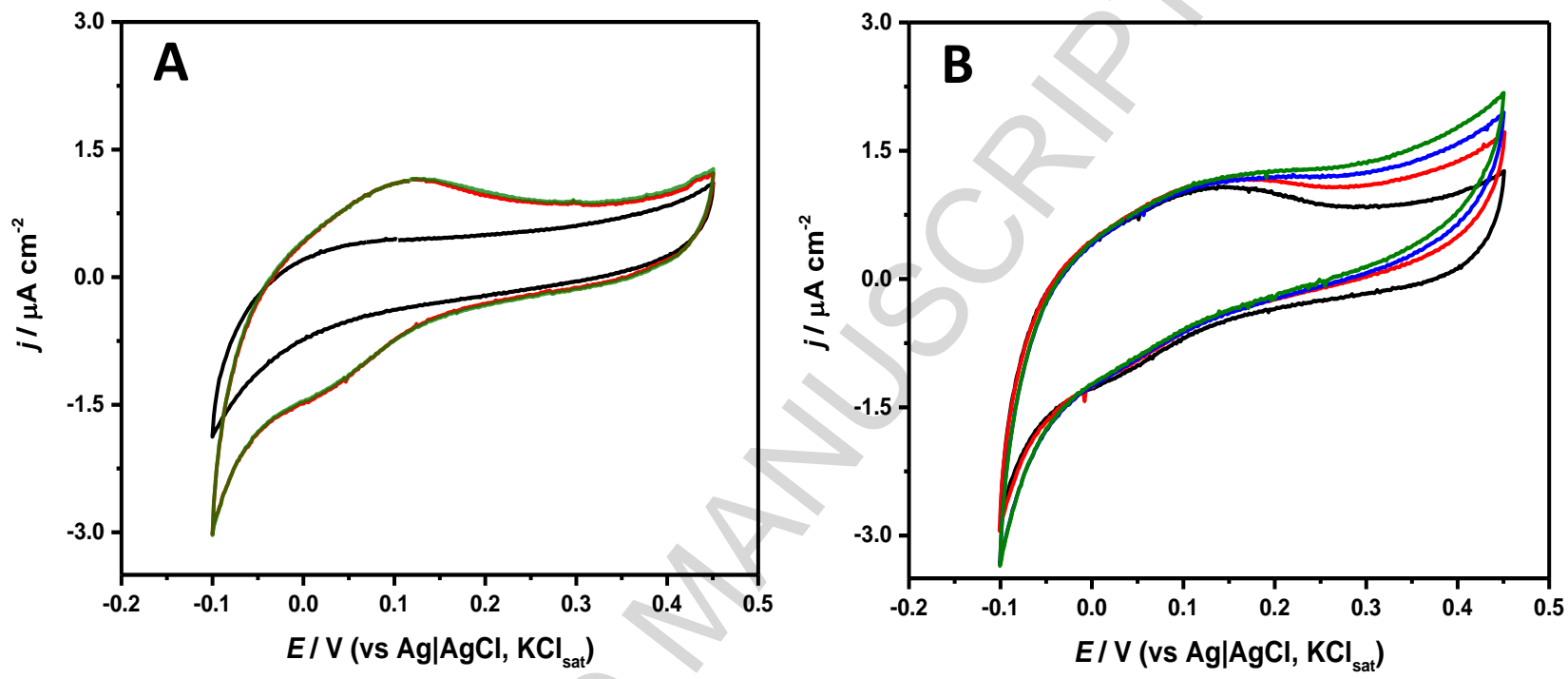

Figure 1. (A) Cyclic voltammograms of bare (black) and cyt $c$ modified GP electrodes in the absence (red) or presence of $3 \mathrm{mM}$ glucose (green). (B) Cyclic voltammograms of PQQ-GDHcyt $c$ bioanode operating at various concentrations of glucose: $0 \mathrm{mM}$ (black), $1 \mathrm{mM}$ (red), $2 \mathrm{mM}$ (blue), $3 \mathrm{mM}$ (green). Scan rate $5 \mathrm{mV} \mathrm{s}^{-1}$.

Apart from functioning as an electron-transfer mediator, the cyt $c$ layer can also be used to accumulate charge due to its faradaic behavior, similarly to that previously reported for redox hydrogels [10,14-16], carbon nanotube/conducting polymer composites [9] or the redox protein rusticyanin [36]. As we can see from the CVs (Figure 1A), biomodification of a bare GP electrode with cyt $c$ resulted in an obvious enhancement of the capacitance due to the redox reactions of the electroactive cyt $c$. Cytochromes of $c$-type in the biofilms of live bacteria gave similar results [4]. Galvanostatic discharging of the PQQ-GDH-cyt $c$-GP bioanode using a $1 \mathrm{~s}$ pulse current of $12 \mu \mathrm{A} \mathrm{cm}{ }^{-2}$ leads to a voltage change of $0.095 \pm 0.005 \mathrm{~V}$ (Figure 2B). The 
corresponding capacitance is calculated as $126 \pm 0.7 \mu \mathrm{F} \mathrm{cm}$ according to Supplementary equation (S2). This value is close to the capacitance value calculated from CV $\left(131 \pm 0.6 \mu \mathrm{F} \mathrm{cm}^{-2}\right)$ using Supplementary equation (S3). The self-charging process occurred spontaneously after completion of the discharging. The catalytic oxidation of glucose by PQQ-GDH thus provides electrons, which are in turn transferred to cyt $c$ through interprotein electron transfer. As a result, the heme groups in cyt $c$ were reduced, which corresponds to a stabilization of the electrode potential at its open circuit potential (OCP) in the fully charged state (Figure 2A, B). In the absence of PQQ-GDH, the cyt $c$-GP electrode displayed a higher OCP of $0.063 \mathrm{~V}$ and a gradually increasing OCP during the charge/discharge cycling (Supplementary Figure S2). A similar phenomenon was observed in a recent work regarding a self-charging biosupercapacitor employing a myoglobin-modified electrode [37].
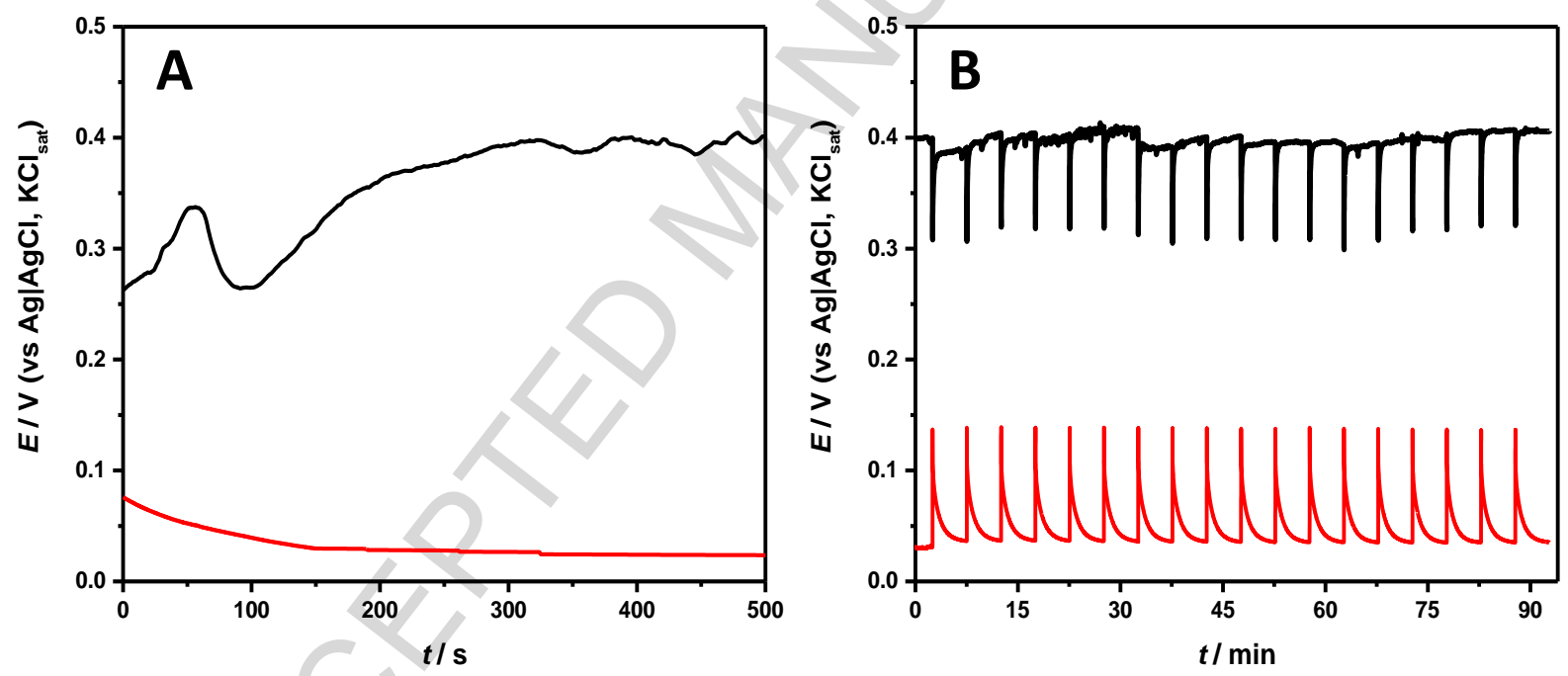

Figure 2. (A) Representative OCP curves and (B) charge/discharge curves of the BOx-GP-cyt $c$ (black) and the PQQ-GDH-cyt $c$-GP (red) electrodes in the presence of $3 \mathrm{mM}$ glucose in the airsaturated buffer solution. Discharge was carried out by applying a pulse current of $12 \mu \mathrm{A} \mathrm{cm}^{-2}$ for $1 \mathrm{~s}$.

\subsection{Electrochemical behavior of the biocathode}


To create a dual-function biocathode (BOx-GP-cyt $c$ ), BOx was immobilized on one side of the GP electrode as energy converting component catalyzing dioxygen reduction, while cyt $c$ was adsorbed on the other side to create a charge storing part. A similar approach of employment charging/capacitive compartments, e.g. enzyme-charging/polyaniline composite-storing and thylakoid membranes-charging/gold nanoparticles-storing patterns, was successfully applied in the construction of hybrid bioelectrochemical systems [5,9]. The BOx modified GP electrode exhibits a stable OCP of $0.50 \pm 0.02 \mathrm{~V}$ after equilibrating for $50 \mathrm{~s}$ in an air-saturated electrolyte (Supplementary Figure S3). The high OCP value indicates a favorable orientation of the type I $\mathrm{Cu}$ center facing the electrode surface, and $\mathrm{BOx}$ is therefore able to accept electrons directly from the electrode. When cyt $c$ was deposited on the other side of the BOx-GP electrode, its initial OCP dropped to $0.26 \mathrm{~V}$, followed by a subsequent increase (Figure 2A). The OCP fluctuations are related to the charge distribution of the biocathode, in other words the dynamic equilibrium between cyt $c$ and BOx. The OCP of the biocathode finally stabilized at $0.40 \pm 0.02$ V. As shown in the CVs of the BOx modified electrodes, the presence of a capacitive cyt $c$ layer also results in a slight decrease in the cathodic limiting current (Supplementary Figure S4). Comparing the discharge results of the BOx-GP (Supplementary Figure S5) and the BOx-GP-cyt $c$ electrodes (Figure 2B), we found that a twice-smaller voltage drop was achieved for the latter, which corresponds to a significant enhancement in the electrode capacitance. The observed increase in the electrode capacitance in the presence of cyt $c$ confirms the practical implementation of the proposed concept that the capacitance of the cyt $c$ layer may ensure a sufficient charge-storing ability of the hybrid biodevice. 

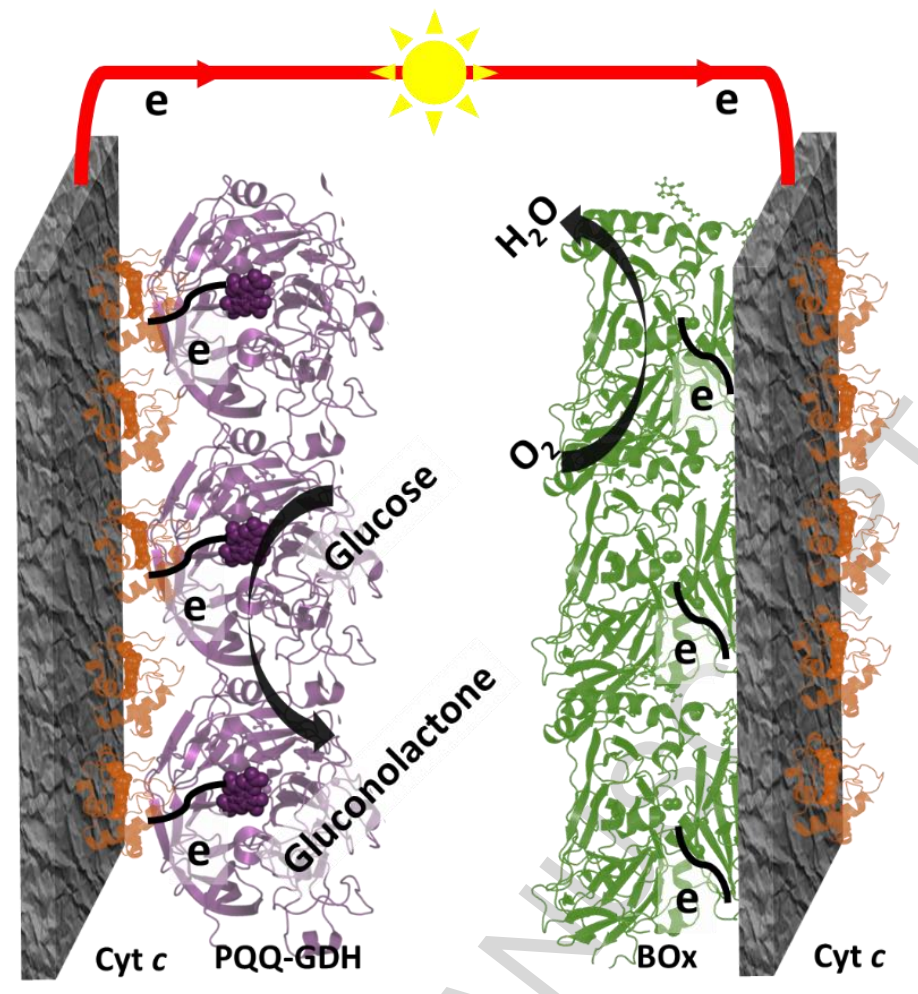

Scheme 1. Schematic representation of the assembled ESBC. The structures of cyt $c$ (rust red), PQQ-GDH (purple) and BOx (green) correspond to PDB 1hrc, 1c9u and 2xll, respectively. Not drawn to scale.

\subsection{Electrochemical behavior of the hybrid ESBC}

We have finally constructed a hybrid ESBC (Scheme 1) by combining the PQQ-GDH-cyt $c$-GP bioanode with the BOx-GP-cyt $c$ biocathode. The fabricated device has an open circuit voltage $(\mathrm{OCV})$ of $0.38 \pm 0.03 \mathrm{~V}$ and a peak power density of $0.29 \mu \mathrm{W} \mathrm{cm}$ at a voltage of $0.16 \mathrm{~V}$ in the continuous mode (Figure 3A). As shown in the polarization curve, in order to polarize the electrode, the voltage drops fast at the beginning due to kinetic, activation and charge transfer losses. After that, the voltage decreases slowly and linearly over a wide range of the current density, resulting from the intrinsic resistance of the system as well as the resistance from the flow of ions in the electrolyte. The mass transport limitation, which usually happens at a potential close to zero, is not a critical factor for determining the current density in our ESBC due to the relative slow kinetics of the enzymes especially at the anode. 
The OCV value achieved is typical for all Nernstian hybrid bioelectrochemical systems with the same charge-storing component at both electrodes $[9,15,16]$. This is indicative of a limited ability to increase the relative amount of oxidized and reduced redox active molecules during the self-charging process. The hybrid ESBC was evaluated by applying different current pulses over a period of $1 \mathrm{~s}$, and the corresponding voltage drops were recorded in Figure 3B. Higher currents applied resulted in larger voltage drops as well as a longer recovery time back to the initial OCP. Since the maximum power density of the ESBC in the beginning of the discharge process is calculated from the OCV and the applied current pulse $\left(4.5 \mu \mathrm{W} \mathrm{cm}{ }^{-2}\right.$ for $\left.12 \mu \mathrm{A} \mathrm{cm}{ }^{-2}\right)$, it does not describe the performance during the discharge process. Alternatively, the voltage in the end of the discharging pulse can be used as a characteristic parameter, as was demonstrated by Agnes et al. [8]. The corresponding power curve profile calculated from the end-point voltage is presented in Figure 3C. The highest power density of $2.6 \pm 0.1 \mu \mathrm{W} \mathrm{cm}$ at a current density between 12-15 $\mu \mathrm{A} \mathrm{cm}^{-2}$ was obtained.

Appling a discharging current pulse of $12 \mu \mathrm{A} \mathrm{cm}$ for $1 \mathrm{~s}$ on the two-electrode system ESBC leads to a voltage drop of $0.14 \pm 0.01 \mathrm{~V}$. The voltage drop remained constant for at least 52 cycles of continuous self-charge/discharge operation, indicating no desorption of the biomolecules (Figure 3D). The overall capacitance of the ESBS calculated from fast galvanostatic discharge was $85 \pm 1 \mu \mathrm{F} \mathrm{cm} \mathrm{cm}^{-2}$, which is slightly higher than that reported for a conventional biosupercapacitor based on the copper protein rusticyanin as the charge-storing redox protein [36]. 

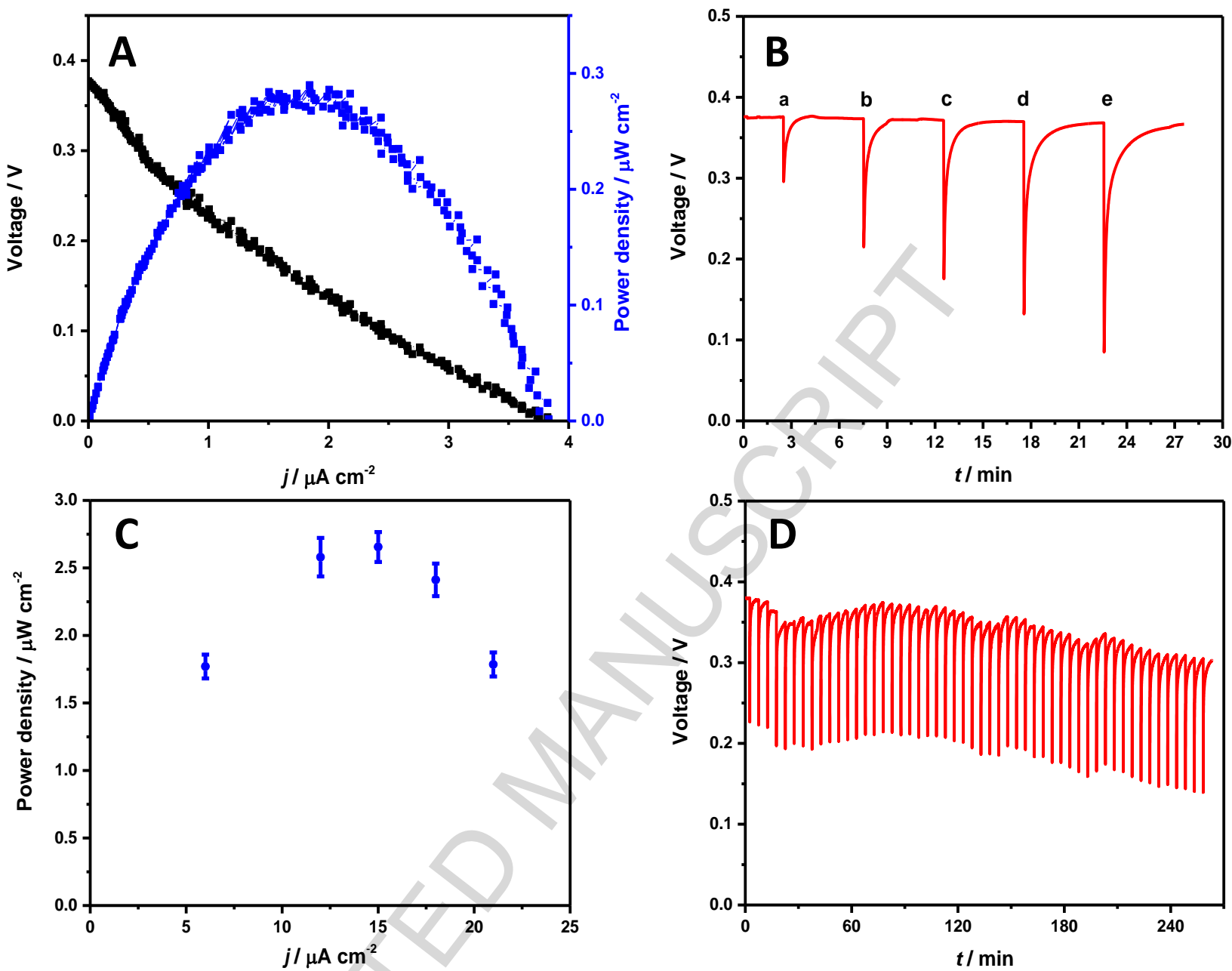

Figure 3. Representative electrochemical performance of the assembled ESBC in the presence of $3 \mathrm{mM}$ glucose. (A) Voltage-current (black) and power-current curves (blue) obtained in continuous mode. Scan rate $1 \mathrm{mV} \mathrm{s}^{-1}$. (B) Charge/discharge curves. Voltage drops were measured by applying different current pulses: (a) $6 \mu \mathrm{A} \mathrm{cm}^{-2}$, (b) $12 \mu \mathrm{A} \mathrm{cm}^{-2}$, (c) $15 \mu \mathrm{A} \mathrm{cm}{ }^{-2}$, (d) $18 \mu \mathrm{A} \mathrm{cm}^{-2}$ and (e) $21 \mu \mathrm{A} \mathrm{cm}^{-2}$ over a period of $1 \mathrm{~s}$. (C) Power-current profile in a pulse mode from the end-point voltage values obtained by applying various current pulses. (D) Longterm charge/discharge behavior. Discharge was carried out using a pulse current of $12 \mu \mathrm{A} \mathrm{cm}$ for $1 \mathrm{~s}$. 
The self-charging process was followed until a stable OCV was achieved and it took around 4 $\min$ and $1 \mathrm{~min}$ for the bioanode and the biocathode, respectively (Figure 2B). The bioanode therefore determined the rate of the self-charging process in the assembled ESBC. A similar effect was reported in a glucose $/ \mathrm{O}_{2}$ biosupercapacitor based on an Os redox polymer [14]. There is a slight fluctuation in the recharged voltage of the ESBC, which accords with the OCP and charging/discharging curve of the BOx-GP-cyt $c$ electrode due to the dynamic equilibrium between BOx and cyt $c$. After 50 cycles of discharging pulses, an OCV of the ESBC with a constant self-charging time applied up to $0.31 \mathrm{~V}$ was recovered, which can be compared with the initial value of $0.38 \mathrm{~V}$. The OCV achieved even after more than $4 \mathrm{~h}$ of operation, however, outperforms a recent example of a glucose/ $\mathrm{O}_{2}$ ESBC employing non-biological capacitive elements [13]. The operational stability is significantly better than that of other reported hybrid bioelectrochemical systems, in which the energy-converting bioelement is interconnected with a charge-storing component with a disproportionately high capacitance [9].

The main operational characteristics of the ESBC achieved in this work, viz. maximum power output, OCV and operational stability, are comparable to those for the analogous hybrid and conventional systems employing potentially implantable electrodes of similar morphology and operating in solutions containing glucose, lactate and ascorbate as fuels (Supplementary Table S1). Taking into account that overall stability of the developed ESBC is mainly determined by the stability of the anodic enzyme, utilization of cyt $c$ as a mediator results in a better stability compared to the direct immobilization on the carbon surface but is inferior to the bioanodes based on osmium-complex-containing polymer matrix.

\section{Conclusions}

In conclusion, we have demonstrated the very first example of a self-charging ESBC hybrid system, in which solely biomolecules (enzymes and a redox protein) are employed to convert and store energy within a single device. Cyt $c$ facilitates the electron transfer between PQQ-GDH and the GP electrode and simultaneously stores charge at both the anode and the cathode. Compared to the low power output in classic biofuel cells, the new ESBC offers a notably higher power output via the pulse mode, while the capacitance was continuously recharged through the 
biocatalytic energy conversion. The introduction of flexible electrode materials makes this new construction principle promising as a real implantable or wearable power source, considering that redox proteins from the hosting organism can be employed in biocompatible charge storing electrodes to overcome the safety issue for operation under both in vitro and in vivo conditions.

\section{Associated Content}

Supporting Information. Supporting equations S1-S3, electrochemical data presented in the five supporting figures and a supporting table representing comparison of analogous membraneless enzymatic bioelectrochemical cells.

\section{Corresponding Authors}

* E-mail: cq@kemi.dtu.dk (Qijin Chi)

* E-mail: lo.gorton@biochemistry.lu.se (Lo Gorton)

\section{Notes}

The authors declare no competing financial interest.

\section{Acknowledgements}

FS is grateful for the $\mathrm{PhD}$ scholarship from China Scholarship Council (CSC 201506170059). DP acknowledges the People Programme (Marie Curie Actions) of the European Union's Seventh Framework Programme (FP7/2007-2013) under REA grant agreement no. 609405 (COFUNDPostdocDTU). LG thanks the Swedish Research Council (project 2014-5908), QC and JZ acknowledge the Danish Council for Independent Research (Project ID: DFF-FTP 12-127447 and the YDUN project, DFF 4093-00297, respectively), and JU acknowledges financial support from the Russian Science Foundation (project 17-13-01274). 


\section{References}

[1] D. Pankratov, P. Falkman, Z. Blum, S. Shleev, A hybrid electric power device for simultaneous generation and storage of electric energy, Energy Environ. Sci. 7 (2014) 989.

[2] A. Deeke, T.H.J.A. Sleutels, H.V.M. Hamelers, C.J.N. Buisman, Capacitive bioanodes enable renewable energy storage in microbial fuel cells, Environ. Sci. Technol. 46 (2012) 3554-3560.

[3] G.D. Schrott, P.S. Bonanni, L. Robuschi, A. Esteve-Nuñez, J.P. Busalmen, Electrochemical insight into the mechanism of electron transport in biofilms of Geobacter sulfurreducens, Electrochim. Acta. 56 (2011) 10791-10795.

[4] N.S. Malvankar, T. Mester, M.T. Tuominen, D.R. Lovley, Supercapacitors based on ctype cytochromes using conductive nanostructured networks of living bacteria, ChemPhysChem. 13 (2012) 463-468.

[5] G. Pankratova, D. Pankratov, K. Hasan, H.-E. Åkerlund, P.-Å. Albertsson, D. Leech, S. Shleev, L. Gorton, Supercapacitive photo-bioanodes and biosolar cells: A novel approach for solar energy earnessing, Adv. Energy Mater. 7 (2017) 1602285.

[6] D. Pankratov, G. Pankratova, T.P. Dyachkova, P. Falkman, H.-E. Åkerlund, M.D. Toscano, Q. Chi, L. Gorton, Supercapacitive biosolar cell driven by direct electron transfer between photosynthetic membranes and CNT networks with enhanced performance, ACS Energy Lett. 2 (2017) 2635-2639.

[7] S. Shleev, E. González-Arribas, M. Falk, Biosupercapacitors, Curr. Opin. Electrochem. 5 (2017) 226-233.

[8] C. Agnès, M. Holzinger, A. Le Goff, B. Reuillard, K. Elouarzaki, S. Tingry, S. Cosnier, Supercapacitor/biofuel cell hybrids based on wired enzymes on carbon nanotube matrices: autonomous reloading after high power pulses in neutral buffered glucose solutions, Energy Environ. Sci. 7 (2014) 1884-1888.

[9] D. Pankratov, Z. Blum, D.B. Suyatin, V.O. Popov, S. Shleev, Self-charging electrochemical biocapacitor, ChemElectroChem. 1 (2014) 343-346.

[10] K.L. Knoche, D.P. Hickey, R.D. Milton, C.L. Curchoe, S.D. Minteer, Hybrid glucose/O $\mathrm{O}_{2}$ biobattery and supercapacitor utilizing a pseudocapacitive dimethylferrocene redox polymer at the bioanode, ACS Energy Lett. 1 (2016) 380-385.

[11] M. Kizling, K. Stolarczyk, P. Tammela, Z. Wang, L. Nyholm, J. Golimowski, R. Bilewicz, Bioelectrodes based on pseudocapacitive cellulose/polypyrrole composite improve performance of biofuel cell, Bioelectrochemistry. 112 (2016) 184-190.

[12] D. Pankratov, Z. Blum, S. Shleev, Hybrid electric power biodevices, ChemElectroChem. 1 (2014) 1798-1807.

[13] T. Bobrowski, E. González Arribas, R. Ludwig, M.D. Toscano, S. Shleev, W. Schuhmann, Rechargeable, flexible and mediator-free biosupercapacitor based on transparent ITO nanoparticle modified electrodes acting in $\mu \mathrm{M}$ glucose containing buffers, Biosens. Bioelectron. 101 (2018) 84-89.

[14] S. Alsaoub, A. Ruff, F. Conzuelo, E. Ventosa, R. Ludwig, S. Shleev, W. Schuhmann, An intrinsic self-charging biosupercapacitor comprised of a high-potential bioanode and a low-potential biocathode, ChemPlusChem. 82 (2017) 576-583.

[15] D. Pankratov, F. Conzuelo, P. Pinyou, S. Alsaoub, W. Schuhmann, S. Shleev, A Nernstian biosupercapacitor, Angew. Chemie - Int. Ed. 55 (2016) 15434-15438. 
[16] X. Xiao, P. Ó Conghaile, D. Leech, R. Ludwig, E. Magner, A symmetric supercapacitor/biofuel cell hybrid device based on enzyme-modified nanoporous gold: An autonomous pulse generator, Biosens. Bioelectron. 90 (2017) 96-102.

[17] A. Zebda, J.P. Alcaraz, P. Vadgama, S. Shleev, S.D. Minteer, F. Boucher, P. Cinquin, D.K. Martin, Challenges for successful implantation of biofuel cells, Bioelectrochemistry. 124 (2018) 57-72.

[18] I.M. Mosa, A. Pattammattel, K. Kadimisetty, P. Pande, M.F. El-Kady, G.W. Bishop, M. Novak, R.B. Kaner, A.K. Basu, C. V. Kumar, J.F. Rusling, Ultrathin graphene-protein supercapacitors for miniaturized bioelectronics, Adv. Energy Mater. (2017) 1700358.

[19] M. Zhang, C. Hou, A. Halder, H. Wang, Q. Chi, Graphene papers: smart architecture and specific functionalization for biomimetics, electrocatalytic sensing and energy storage, Mater. Chem. Front. 1 (2017) 37-60.

[20] M. Zhang, A. Halder, X. Cao, C. Hou, Q. Chi, Graphene-paper based electrochemical sensors, in: M. M. Rahman, A. M, Asiri (Eds), Electrochemical Sensors Technology, IntechOpen., London, 2017, pp. 33-62.

[21] M. Zhang, A. Halder, C. Hou, J. Ulstrup, Q. Chi, Free-standing and flexible graphene papers as disposable non-enzymatic electrochemical sensors, Bioelectrochemistry. 109 (2016) 87-94.

[22] N. Zhu, S. Han, S. Gan, J. Ulstrup, Q. Chi, Graphene paper doped with chemically compatible Prussian blue nanoparticles as nanohybrid electrocatalyst, Adv. Funct. Mater. 23 (2013) 5297-5306.

[23] N. Aryal, A. Halder, M. Zhang, P.R. Whelan, P.L. Tremblay, Q. Chi, T. Zhang, Freestanding and flexible graphene papers as bioelectrochemical cathode for selective and efficient $\mathrm{CO}_{2}$ conversion, Sci. Rep. 7 (2017) 9107.

[24] Z. Niu, J. Chen, H.H. Hng, J. Ma, X. Chen, A leavening strategy to prepare reduced graphene oxide foams, Adv. Mater. 24 (2012) 4144-4150.

[25] A. Halder, M. Zhang, Q. Chi, Electroactive and biocompatible functionalization of graphene for the development of biosensing platforms, Biosens. Bioelectron. 87 (2017) 764-771.

[26] M. Falk, V. Andoralov, M. Silow, M.D. Toscano, S. Shleev, Miniature biofuel cell as a potential power source for glucose-sensing contact lenses, Anal. Chem. 85 (2013) 6342 6348.

[27] S.C. Feifel, A. Kapp, R. Ludwig, F. Lisdat, Nanobiomolecular multiprotein clusters on electrodes for the formation of a switchable cascadic reaction scheme, Angew. Chemie Int. Ed. 53 (2014) 5676-5679.

[28] C. Wettstein, H. Möhwald, F. Lisdat, Coupling of pyrroloquinoline quinone dependent glucose dehydrogenase to (cytochrome $c /$ DNA)-multilayer systems on electrodes, Bioelectrochemistry. 88 (2012) 97-102.

[29] W. Jin, U. Wollenberger, F.F. Bier, A. Makower, F.W. Scheller, Electron transfer between cytochrome $c$ and copper enzymes, Bioelectrochem. Bioenerg. 39 (1996) 221-225.

[30] E.E. Ferapontova, T. Ruzgas, L. Gorton, Direct electron transfer of heme- and molybdopterin cofactor-containing chicken liver sulfite oxidase on alkanethiol-modified gold electrodes, Anal. Chem. 75 (2003) 4841-4850.

[31] V. Fridman, U. Wollenberger, V. Bogdanovskaya, F. Lisdat, T. Ruzgas, A. Lindgren, L. Gorton and F. W. Scheller, Electrochemical investigation of cellobiose oxidation by cellobiose dehydrogenase in the presence of cytochrome $c$ as mediator, Biochem. Soc. 
Trans. 28 (2000) 63-70.

[32] S. Shleev, J. Tkac, A. Christenson, T. Ruzgas, A.I. Yaropolov, J.W. Whittaker, L. Gorton, Direct electron transfer between copper-containing proteins and electrodes, Biosens. Bioelectron. 20 (2005) 2517-2554.

[33] F. Lisdat, Trends in the layer-by-layer assembly of redox proteins and enzymes in bioelectrochemistry, Curr. Opin. Electrochem. 5 (2017) 165-172.

[34] D. Ciornii, M. Riedel, K.R. Stieger, S.C. Feifel, M. Hejazi, H. Lokstein, A. Zouni, F. Lisdat, Bioelectronic circuit on a 3D electrode architecture: Enzymatic catalysis interconnected with photosystem I, J. Am. Chem. Soc. 139 (2017) 16478-16481.

[35] S. Pinck, M. Etienne, M. Dossot, F.P.A. Jorand, A rapid and simple protocol to prepare a living biocomposite that mimics electroactive biofilms, Bioelectrochemistry. 118 (2017) 131-138.

[36] E. González-Arribas, M. Falk, O. Aleksejeva, S. Bushnev, P. Sebastián, J. M. Feliu, S. Shleev, A conventional symmetric biosupercapacitor based on rusticyanin modified gold electrodes, J. Electroanal. Chem. 816 (2018) 253-258.

[37] D. Pankratov, F. Shen, R. Ortiz, M.D. Toscano, E. Thormann, J. Zhang, L. Gorton, Q. Chi, Fuel-independent and membrane-less self-charging biosupercapacitor, Chem. Commun. 54 (2018) 11801-11804.

[38] N. Mano, A. de Poulpiquet, $\mathrm{O}_{2}$ reduction in enzymatic biofuel cells, Chem. Rev. 118 (2018) 2392-2468. 


\section{Highlights}

- The device employing biomolecules for energy conversion and storage was developed.

- PQQ-GDH and BOx were utilized as anodic and cathodic bioelements, respectively.

- Cyt $c$ was used as an anodic mediator and as a redox active charge-storing unit.

- The main characteristics were comparable to those for analogous systems. 